INTERNATIONAL DESIGN CONFERENCE - DESIGN 2018

https://doi.org/10.21278/idc.2018.0108

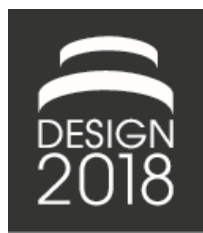

\title{
INTRODUCING SUSTAINABILITY IN ENGINEERING DESIGN EDUCATION: A CASE STUDY USING ANALYSIS OF IMPACTS DURING THE DESIGN FOR SUSTAINABILITY (AID-DS)
}

\author{
I. E. Esparragoza, J. A. Mesa and H. E. Maury
}

\begin{abstract}
This work presents an academic initiative to introduce sustainability in engineering design education based on a case study approach that uses indicators to measure the sustainability performance of a product. The proposed approach uses strategic actions to redesign the product and to measure the sustainability performance under the new conditions. The performances of different alternatives resulting from the strategic interventions are compared to determine the most sustainable solution considering the effect of the strategic actions on the three pillars of sustainability.
\end{abstract}

Keywords: sustainable design, design education, design strategy

\section{Introduction}

Sustainability is becoming an important and in many cases standard practice for the development of new products and services (Feng and Mai, 2015). However, the application of sustainability principles in the design of products is challenging due to the complexity of the concept, the poor understanding of the interaction between the different dimensions of sustainability, and the lack of standard methodologies and indicators (Hallstedt, 2017). Another challenging fact that has been identified is the lack of awareness and mindset toward sustainability in the general population and, of particular interest, in engineering students (UNESCO, 2003). A literature review shows that researchers in the academia are looking for methodologies and educational practices to better prepare future engineers as responsible citizens and designers who can develop new products and systems in a sustainable fashion (Clark, 2003; Rowe, 2007; Kajikawa, 2008; Brundiers and Wiek, 2010). Several approaches such as (Szendiuch, 2007) have been documented on sustainable design and most of them have a strong emphasis on the environment, e.g. eco-design, with minimum attention to the other pillars of sustainability. Engineering education efforts around the world point toward the formation of future engineers with the awareness, knowledge and attitude for responsible design; however, the limited scope on sustainability considering only the environmental dimension is creating an overall perception that sustainability is mainly about green design. An adequate educational initiative should provide a methodological approach that considers a responsible stewardship of sustainability by effectively balancing environmental, economic and social factors in the design using appropriate indicators. At the same time, the academic experience should foster a change in the mindset of students that triggers the interest and motivation for a sustainable lifestyle and the use of sustainable design in the professional practice.

This work presents a module on sustainability that can be introduced in an existing introductory design course. This module uses a holistic approach considering the three dimensions of sustainability, and it is based on the analysis of impacts during the design for sustainability as a means to understand the 
effect of the decision-making process on sustainability indicators during the design. The next section explains the issues related to the introduction of sustainability in engineering design education followed by the learning approach proposed for the module. Since the module is based on the analysis of sustainability impacts, the methodology to be used is presented, finalizing with a case study to illustrate the use of this approach under the proposed framework.

\section{Sustainability in engineering design education}

Introducing sustainability into engineering design education is considered one of the most complex challenges and paradigms in the last years (Fien, 2002). This involves the encourage of competences, behaviors and thinking to develop engineering projects and activities taking into account the relevance of the adverse impacts and the awareness regarding the consequences associated with sustainability. The sustainability concept is commonly integrated into engineering curriculums through courses and module courses focused on four dominant means (Murphy et al., 2009):

- Use of tools designed to address complex systems such LCA;

- Development of sustainability concepts using traditional courses based on lectures;

- Study of clean technologies for developing sustainable engineering solutions;

- Development of cross-interdisciplinary courses.

Means mentioned are commonly developed in project-based courses aiming the comprehension and acquisition of knowledge, skills, commitment and social role thinking. Some approaches in project-led and problem based learning can be found in Guerra (2014) and Mesquita et al. (2009). However, the integration of sustainability in introductory design engineering courses during the first year of study requires addressing issues such as:

- Students lack of knowledge concerning sustainability and its relationship to engineering;

- The need of adapting the sustainability dimensions, tools and approaches to generate contents and learning materials at a very basic level;

- The difficult related to the sustainable thinking and the social and cultural heterogeneity in the new engineering students;

- Poor understand regarding the influence of design decision making on the sustainability performance of engineering solutions obtained.

These issues demand the integration of sustainability in a basic or beginner level, establishing the dimensions, indicators and strategies related to the enhancement of common engineering tasks. This, with the aim of motivating and encouraging first year engineering students to facilitate further implementations and immersions on sustainability topics during the undergraduate studies.

\section{Learning approach}

The aim of the proposed learning approach is to expose students to and active educational experience where they can learn by analysing the impacts of the decisions made during the design process on the sustainability of a final product. The learning approach was developed following the Engaged Learning Template (Nagel et al., 2016), and it consists of a learning module that can be incorporated in an introductory engineering design course. The main characteristics of the learning module are summarized below:

1. Learning Environment: This is a course module that it can be incorporated in an introductory course of engineering design.

2. Learning Outcomes: After completion of this module, students should be able to:

a. Define sustainability from the engineering perspective in a holistic way taking into consideration the environmental, economic and social dimensions.

b. Determine the impact of design decisions on the product sustainability by using appropriate indicators.

c. Apply strategies to improve the sustainability performance of a product.

d. Select the most sustainable solution among a group of alternatives concepts. 
3. Teaching Strategies: This module is designed to use different teaching strategies to cover the desired material and to get students engaged in the learning experience. This module should be introduce after students have studied the design process and could be used to redesign a product using the existing product as reference, or to design a new product and compare different alternatives. The main strategies proposed are:

a. Lecture: Instructor introduces the module, explains the learning objectives, defines basic concepts and assigns research questions to students.

$b$. Research-based learning: Students work in small groups to seek for the answers to the questions posted by the instructor.

c. Case Study: Students work in small groups to analyze a real case and use sustainability performance indicators in all three dimensions and thinking skills to select the most sustainable concept.

4. Module Content: The proposed module will cover the following topics:

a. Sustainability definition: Fundamental concepts of sustainability are discussed from the engineering perspective using a holistic approach where the environmental, economic and social pillars are considered.

b. Sustainable product design: A comprehensive approach to design for sustainability is studied including requirements, specifications, and design principles using a holistic approach.

c. Sustainability performance indicators: Sustainability performance indicators are introduced to measure product's performance and to compare the performance with other alternatives.

d. Analysis of Impacts and Design Strategies: The impacts on sustainability based on the analysis of performance indicators are presented and design strategies are discussed to enhance sustainability performance.

5. Assessment: Two different types of assessments will be used for the module.

a. Assessment for Learning: This assessment is designed to determine the effectiveness of the module to reach the desired learning goal. This assessment comprises two steps: a pre or diagnosis assessment and a post or formative assessment. For this purpose, a survey will be used before and after students are exposed to the learning module. A comparison of the pre and post results will determine the effectiveness of the experience and provide useful information for improvement. This assessment will not be part of the students' grade.

b. Assessment of Learning: This assessment will evaluate the performance of students in the learning module. In this case, specific performance indicators and rubrics will be used and this assessment will be part of the students' grade for the course.

6. Target Audience: the module is designed for engineering students in an introductory course of design. Students are not required to be in any specific discipline of engineering; however, the case study used as an example in this paper is more appropriate for students in a mechanical design field. In any case, students from all engineering disciplines can benefit from this module and cases in other engineering disciplines can be adapted to the module.

\section{Analysis of sustainability impacts}

This section introduces the analysis of sustainability impacts approach used in the learning module. The product development process produces impacts affecting environmental, economic and social dimensions. The consolidation and simultaneously measurement of these impacts define the sustainability performance of the product throughout the development process. The objective of establishing a sustainability performance is to assess and improve the overall performance of a product or to enhance specific indicators of interest according to the requirements and the importance given by the design team (Luglietti et al., 2016).

The analysis of sustainability impacts is proposed as an approach to establish sustainability indicators associated to any process involved during the lifecycle of products (manufacturing, use or final disposal) to measure sustainability performance to compare alternatives solutions. The Analysis of Impacts during Design for Sustainability (AID-DS) method includes five steps that are defined below, and Figure 1 illustrates the steps and outputs of this methodology. 


\section{OUTPUTS BY STEP}
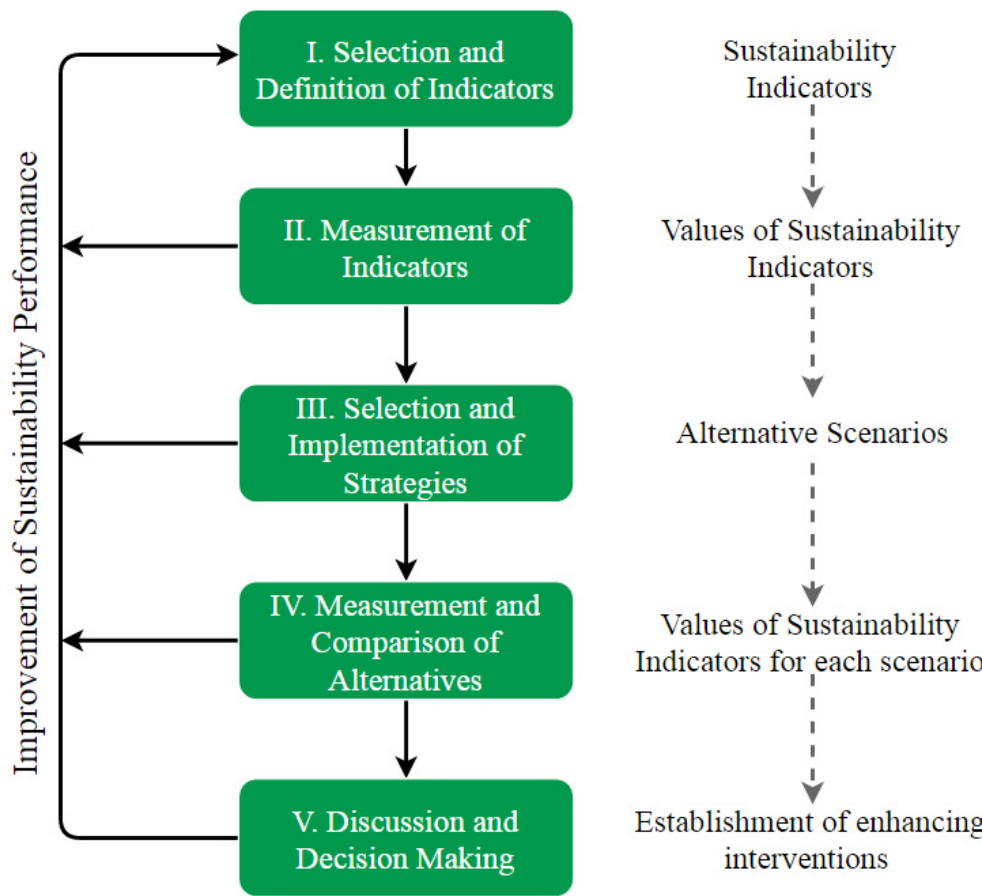

Alternative Scenarios

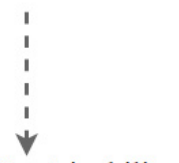

Values of Sustainability Indicators for each scenario

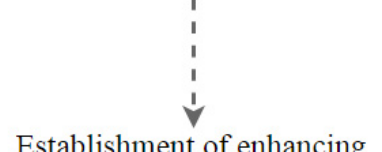

Establishment of enhancing interventions

Figure 1. (AID-DS) methodology and outputs by steps

I-Selection and Definition of Indicators: the impacts in sustainability during the product development can be negative or positive. In this approach, sustainability indicators are established based on negative impacts. In the proposed learning module, the environmental indicators are associated to consumptions of energy and raw material, waste of raw material and emissions released (Sarkar et al., 2011); economic indicators are associated to the costs, profits and issues of the business; and social indicators are associate to the health of workers and the community. The indicators are limited in this case because the module is to be used in an introductory course.

A set of generic impacts are proposed to facilitate the definition and selection of suitable indicators. Table 1 shows the list of generic impacts that are common to any manufacturing process. Once the indicators are defined, it is recommendable in this step to define the meaning and scope of each indicator, with the aim of avoiding mistakes in their interpretation among the design team.

An example of using tables and table captions can be seen below (Table 1).

Table 1. Generic impacts for the selection and definition of indicators

\begin{tabular}{|l|l|}
\hline Dimensions & Generic Impacts \\
\hline \multirow{3}{*}{ Environmental } & Consumption of Materials and Energy \\
\cline { 2 - 2 } & Waste production \\
\cline { 2 - 2 } & Emissions \\
\hline Economic & Costs (material, energy, worker, process) \\
\hline Social & Health deterioration of workers and community \\
\hline
\end{tabular}

The indicators employed in this approach are exclusively direct indicators, which depends only on the measurable parameters that does not require sources such as surveys, psychometric analysis or posteriors studies for acquiring the data required. Generally, the latter indicators are associated to social issues or corporate policies. 
Several sources can be used to facilitate the selection and definition of indicators. Databases and repositories related to sustainability are available online and the most commonly used are:

- SMIR - Sustainable Manufacturing Indicator Repository http://www.mel.nist.gov/div826/msid/SMIR

- Sustainable Measures http://www.sustainablemeasures.com/indicator-search

- Dantes - Environmental Performance Indicators-EPI http://www.dantes.info/Tools\&Methods/Environmentalinformation/enviro_info_spi_epi.html

II-Measurement of Indicators (Diagnosis): once the indicators are selected and defined it is necessary to evaluate them in the reference product. Databases and software can be useful during this task. Some recommended software and online sites are:

- CES Selector - Edupack www.grantadesign.com/products

- Ecoinvent http://www.carbonfootprint.com/ecoinvent.html

- Simapro https://www.pre-sustainability.com/simapro

- TOXNET https://toxnet.nlm.nih.gov/

- MatWeb http://www.matweb.com/

- Trophec - Trophic Economics model - http: www.trophec.com

In the case of advanced software tools, Solidworks ${ }^{\circledR}$ and Autodesk ${ }^{\circledR}$ provide environmental and sustainability assessment tools that support the decision-making process from the CAD modeling of products.

III-Selection and Implementation of Strategies: in this state the interventions or modifications to the reference product must be defined. The analysis of sustainability impacts does not propose specific strategies or interventions in the reference product. This decision is responsibility of the designer or design team; however, some recommended interventions are listed below:

- Change the material or materials

- Change the manufacturing process

- Change the material and manufacturing process

- Change the geometry and shape of the product

It is important to take into account that the use of CAD/CAE Software is highly recommended when the strategies are implemented (Leibrecht, 2005). CAD/CAE tools provide useful information from early design stages and the further negative impacts can be mitigated early in the design (Bogue, 2014).

IV-Measurement and Comparison of Alternatives: this step consists of the measurement of the sustainability indicators in the alternatives generated throughout the implementation of step III. The considerations and tasks in this step are the same employed in the reference product measurement. Table 2 shows a recommended format to present the data.

The comparison of alternatives is realized using the Pugh method of alternative comparison, in which the performances of indicators of the alternatives are measured with respect to another one; in this case the reference product. The Pugh method is selected because it will provide a normalized matrix of values that is represented in a radial chart with the aim of comparing graphically the results. Table 3 shows a recommended structure for the normalized values based on Table 2 .

Table 2. Values of sustainability indicators for reference product and alternatives

\begin{tabular}{|c|c|c|c|c|}
\hline Sustainability Indicators & $\boldsymbol{R P}$ & $\boldsymbol{A 1}$ & $\boldsymbol{A 2}$ & $\boldsymbol{A n}$ \\
\hline$S I_{1}$ & $R P_{1}$ & $A 1_{1}$ & $A 2_{1}$ & $A n_{1}$ \\
\hline$S I_{2}$ & $R P_{2}$ & $A 1_{2}$ & $A 2_{2}$ & $A n_{2}$ \\
\hline$S I_{3}$ & $R P_{3}$ & $A 1_{3}$ & $A 2_{3}$ & $A n_{3}$ \\
\hline$\ldots$ & $\ldots$ & $\ldots$ & $\ldots$ & $\ldots$ \\
\hline$S I_{n}$ & $R P_{n}$ & $A 1_{n}$ & $A 2_{n}$ & $A n_{n}$ \\
\hline
\end{tabular}


Table 3. Normalized values of sustainability indicators for reference products and alternative

\begin{tabular}{|c|c|c|c|}
\hline $\boldsymbol{R P} / \boldsymbol{R P}$ & $\boldsymbol{A 1 / R P}$ & $\boldsymbol{A 2 / R \boldsymbol { P }}$ & $\boldsymbol{A 3} / \boldsymbol{R} \boldsymbol{P}$ \\
\hline 1.0 & $A 1_{1} / R P_{1}$ & $A 2_{1} / R P_{1}$ & $A 3_{1} / R P_{1}$ \\
\hline 1.0 & $A 1_{2} / R P_{2}$ & $A 2_{2} / R P_{2}$ & $A 3_{2} / R P_{2}$ \\
\hline 1.0 & $A 1_{3} / R P_{3}$ & $A 2_{3} / R P_{3}$ & $A 3_{3} / R P_{3}$ \\
\hline 1.0 & $\ldots$ & $\ldots$ & $\ldots$ \\
\hline 1.0 & $A 1_{n} / R P_{n}$ & $A 2_{n} / R P_{n}$ & $A 3_{n} / R P_{n}$ \\
\hline
\end{tabular}

In the tables above, $S I_{n}$ means the particular sustainability indicator; $R P_{i}$ represents the measurement of the indicators for the reference product; $A n$ represents the alternatives solutions or designs; $A n_{i}$ represents the measurement of the indicators for each alternative design.

$V$-Discussion and Decision Making: the results of the graphical charts provide useful information about the influence of the selected strategies over the product sustainability performance. The values of sustainability indicators can vary increasing and decreasing depending on the strategy implemented. The further analysis and decision making of alternatives should consider these results in order to decide which strategy is more suitable according to the criteria of the design team.

The analysis of sustainability impacts does not consider unequal importance between sustainability indicators; however, the use of weighted methods, hierarchy analysis (Qian et al., 2007), or fuzzy logic (Ghadimi et al., 2012) can be used in those cases.

\section{Case study}

In the learning module, once students have been exposed to basic concepts on sustainability and to the AID-DS method presented in the previous section, they work in a case study where they will be able to apply the concepts and the AID-DS method while analysing a product design.

The case study consists of a single and small product that can be designed and manufactured by students using additive 3D printing. In this work, an example of a chip bag clip is used to illustrate the proposed approach. The CAD model of the product was obtained from a website dedicated to share 3D models (Thingiverse http://www.thingiverse.com/thing:1212828.) A view of the model is shown in Figure 2. Material is assigned in the CAD model and material and geometrical properties for the product are recorded. 3D printing technique is used to create the product and the additive material is identified (see Figure 3). Once the product is printed, the analysis of sustainable indicators takes place. At this time, two set of indicators can be used: one for the original material assigned in the CAD model and one for the material used for 3D printing. CES Edupack is used to find the indicators taking into account materials and manufacturing process. This first analysis will provide the first comparison for sustainability. In this case, the only strategic intervention has been the change of material. Other options can be considered including other strategic interventions, e.g., changing material and manufacturing process, and the information is recorded in the table designed for this technique (see Appendix A).

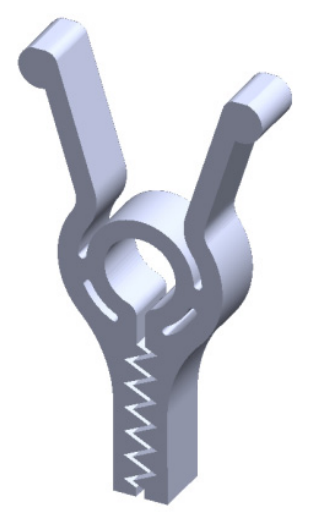

Figure 2. AID-DS methodology and outputs by steps 


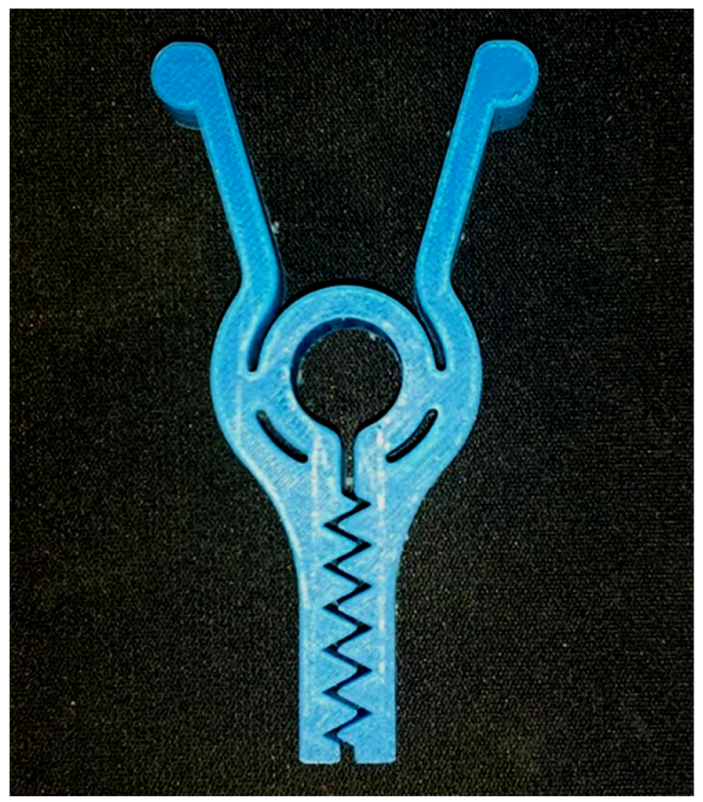

Figure 3. Acknowledgment AID-DS methodology and outputs by steps

The data for the chip bag clip is summarized in Table 4. For the example presented, three different strategic actions were considered and evaluated. In the original product, the material is Polyamide (PA) and the manufacturing process is Selective Laser Sintering (SLS). This is considered the reference product for this analysis.

Environmental and economic indicators are taken from CES Edupack as mentioned before while social indicators in this case study are risks measurements according to the office of Occupational Safety and Health Administration (OSHA, 2017) and taking into account the severity and probability of occurrence of an event associated with the risks of the manufacturing process and the material used. The qualitative scale for these indicators are Low, Medium, High, which are equivalent to 1, 2 and 3 in terms of quantitative values.

Table 4. Values of sustainability indicators for reference product - chip bag clip manufactured in PA and through SLS (steps I and II)

\begin{tabular}{|l|l|l|}
\hline Dimension & Indicator & Value \\
\hline \multirow{4}{*}{ Environmental } & Mass Consumption & $0.0079 \mathrm{~kg}$ \\
\cline { 2 - 3 } & Waste Generated & $0.0005 \mathrm{~kg}$ \\
\cline { 2 - 3 } & Energy Consumption & $0.1734 \mathrm{MJ}$ \\
\cline { 2 - 3 } & $\mathrm{CO}_{2}$ generated & $0.0129 \mathrm{~kg}$ \\
\hline \multirow{3}{*}{ Economic } & Cost of material consumed & $0.1228 \mathrm{USD}$ \\
\cline { 2 - 3 } & Cost of energy consumed & $0.0163 \mathrm{USD}$ \\
\cline { 2 - 3 } & Production Rate & $0.565 \mathrm{units} / \mathrm{h}$ \\
\hline \multirow{3}{*}{$\begin{array}{l}\text { Social } \\
\text { (Worker-based) }\end{array}$} & Risk associated to material & Low \\
\cline { 2 - 3 } & Risk associated to process & Medium \\
\hline
\end{tabular}

The first strategic action (Strategy 1) is to change the material only for Acrylonitrile Butadiene Styrene (ABS). The second strategic action (Strategy 2 ) is to change the manufacturing process only by Fused Deposition Modeling (FDM). Finally, the third strategic intervention (Strategy 3) presented in this case consists of using ABS as material and FDM. In the latter case, both materials and manufacturing process are changed. Table 5 shows the values of the sustainability indicators for the reference product and the alternatives generated after the implementation of strategies. Table 6 shows the normalized values of the sustainability indicators. (Steps III and IV of the AID-DS approach). 
Table 5. Values of sustainability indicators. Reference product and strategies

\begin{tabular}{|l|c|c|c|c|}
\hline Sustainability Indicator & Reference Product & Strategy 1 & Strategy 2 & Strategy 3 \\
\hline Mass Consumption (kg) & 0.0080 & 0.0094 & 0.0051 & 0.0060 \\
\hline Waste Generated (kg) & 0.0005 & 0.0006 & 0.0003 & 0.0004 \\
\hline Energy Consumption (MJ) & 0.1734 & 0.0570 & 0.1107 & 0.0364 \\
\hline CO2 generated (kg) & 0.0130 & 0.0043 & 0.0083 & 0.0027 \\
\hline Cost of material (USD) & 0.1228 & 0.0245 & 0.0784 & 0.0157 \\
\hline Cost of energy consumed (USD) & 0.0164 & 0.0054 & 0.0105 & 0.0034 \\
\hline Production Rate & 0.5650 & 0.5650 & 0.5650 & 0.5650 \\
\hline Risk associated to material & 1.0 & 2.0 & 1.0 & 2.0 \\
\hline Risk associated to process & 2.0 & 2.0 & 1.0 & 1.0 \\
\hline
\end{tabular}

Table 6. Normalized values for sustainability indicators. Reference product and strategies

\begin{tabular}{|l|c|c|c|c|}
\hline Sustainability Indicator & Reference Product & Strategy 1 & Strategy 2 & Strategy 3 \\
\hline Mass Consumption (kg) & 1.0 & 1.1737 & 0.6383 & 0.7492 \\
\hline Waste Generated (kg) & 1.0 & 1.1737 & 0.6383 & 0.7492 \\
\hline Energy Consumption (MJ) & 1.0 & 0.3284 & 0.6383 & 0.2096 \\
\hline CO2 generated (kg) & 1.0 & 0.3291 & 0.6383 & 0.2100 \\
\hline Cost of material (USD) & 1.0 & 0.1997 & 0.6383 & 0.1275 \\
\hline Cost of energy consumed (USD) & 1.0 & 0.3284 & 0.6383 & 0.2096 \\
\hline Production Rate & 1.0 & 1.0 & 1.0 & 1.0 \\
\hline Risk associated to material & 1.0 & 2.0 & 1.0 & 2.0 \\
\hline Risk associated to process & 1.0 & 1.0 & 0.5 & 0.5 \\
\hline
\end{tabular}

The comparisons of the results for the four cases considered are presented in a graphical form as show in Figure 4. From this graph, the alternatives are easily compared for sustainability. The reference concept is the one closest to the unit circle of the graph. Those indicators inside the unit circle represent an improvement on sustainability due to the strategic actions and those larger than the unit circle represent deterioration due to the strategic action.

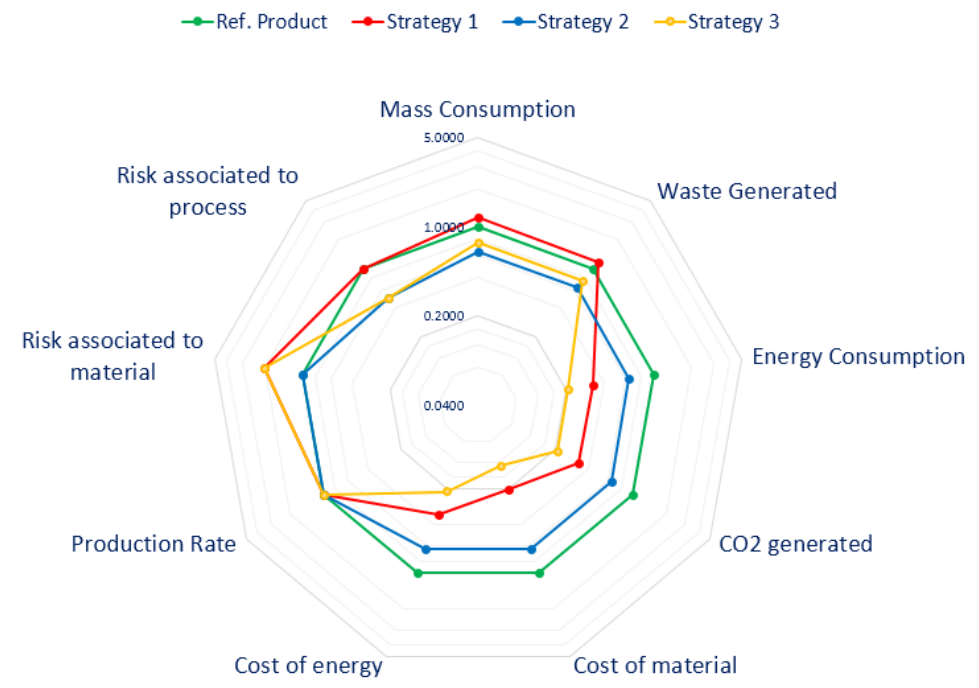

Figure 4. Graphical comparison of reference product vs three strategic interventions proposed 
(Step V) Discussion about the case study: the alternatives obtained from the strategies implementation provide significant improvements in the environmental and economic indicators.

Alternative 1 offers significant reductions in four indicators; light increases in two environmental indicators and an important increase in the risk associated to material. Alternative 2 provide reductions on seven indicators and it keeps constant in two indicators; nevertheless, is the alternative with less reduction respect the reference product. The alternative 3 presents the best overall improvement; however, also this alternative increase of the risk associated to the material.

To the designer: It is recommended to employ the strategy 3 and increase controls and safety rules to mitigate the risk involved.

\section{Scalability: Levels of implementation}

The module presented here is intended for an introductory design course at a freshmen level. However, the analysis of sustainability impacts can be integrated to the engineering curricula following progressive steps that provide a major understanding at the end of the engineering program. Table 7 describes the recommended degrees in the implementation of the method proposed according to the student level. In the first and second year, it is recommended to assist in the selection of indicators and strategies. In the third year, students must be able to work almost independently. In the senior level, students should be able to employ the method and to present detailed analysis, conclusions and recommendations to the design process for the case study product.

The stages of the AID-DS method aim to encourage student's competences in sustainability related to the development of products and its impacts during the product lifecycle. Thus, the student is stimulated to address efforts in the following components:

- The holistic or systemic thinking and analysis;

- Knowledge of interconnected ecological, social, economic systems;

- Transdisciplinarity;

- Reflexivity and social action/engagement.

Table 7. Degrees of implementation of AID-DS method

\begin{tabular}{|l|c|c|c|c|c|}
\hline & \multicolumn{5}{|c|}{ Stages of the Analysis of Sustainability Impacts Method } \\
\hline Student Level & I & In & III & IV & V \\
\cline { 1 - 5 } Freshman & I & Reference & Strategies & Radial Charts & Conclusion \\
\cline { 1 - 5 } Sophomore & AI & S & I & S & AI \\
\cline { 1 - 2 } Junior & S & S & AI & S & S \\
\hline Senior & & & & S & S \\
\hline
\end{tabular}

S: Student

I: Given by the instructor

AI: Assisted by the Instructor

Results after the implementation of the AID-DS method will provide data regarding the evolution and domain of the components mentioned previously. Results and effectiveness of the method will be summarized in future works. Additional studies can be developed from the implementation of the proposed method in second, third and fourth year students as well.

\section{Conclusions}

It is expected that the immersion of the students in this module and the use of the case study will allow them to understand better the complex concept of sustainability and the impact on the different pillars of the decisions made during the design process. The proposed approach here is limited to the use of strategic actions during the design process and the analysis of the impacts of those actions on 
sustainability performance of the product. Other approaches such as life cycle assessment will be more appropriate once students have more engineering concepts and a strong grasp of sustainable design.

The module and case study presented here has been developed for a first year introductory design course. Its implementation and assessment will take place during the spring 2018 and the results will be presented next year. Therefore, the impact on the student learning and competences concerning sustainability will be measured after the implementation of the module.

\section{Acknowledgment}

This work has been partially supported by COLCIENICAS through the PhD National Scholarship Program No 617-2 Contract UN-OJ-2014-24072 and by the Engineering Technology and Commonwealth Engineering (ETCE) Research Development Grant (RDG). Special acknowledgments to srwilson58 from Thingiverse, http://www.thingiverse.com/thing:1212828.

\section{References}

Bogue, R. (2014), "Sustainable manufacturing: acritical discipline for the twenty-first century", Assembly Automation, Vol. 34 No. 2, pp. 117-122. https://doi.org/10.1108/aa-01-2014-012

Brundiers, K. and Wiek, A. (2010), "Educating students in real-world sustainability research: vision and implementation”, Innovative Higher Education, Vol. 36 No. 2, pp. 107-124. https://doi.org/10.1007/s10755010-9161-9

Clark, W. (2003), Institutional needs for sustainable science. Posted to the initiatives of science and technology for sustainability. [online] Harvard University, USA. Available at: https://sites.hks.harvard.edu/sustsci/ists/docs/clark_governance4ss_030905.pdf (accessed 03.04.2017).

Feng, C. and Mai, Y. (2015), "Sustainability assessment of products based on fuzzy multi-criteria decision analysis", The International Journal of Advanced Manufacturing Technology, Vol. 85, pp. 695-710. https://doi.org/10.1007/s00170-015-7978-1

Fien, J. (2002), “Advancing sustainability in higher education: issues and opportunities for research", Higher Education Policy, Vol. 15 No. 2, pp. 143-152. https://doi.org/10.1016/s0952-8733(02)00005-3

Ghadimi, P., Azadnia, A., Mohd Yusof, N. and Mat Saman, M. (2012), “A weighted fuzzy approach for product sustainability assessment: a case study in automotive industry", Journal of Cleaner Production, Vol. 33, pp. 10-21. https://doi.org/10.1016/j.jclepro.2012.05.010

Guerra, A. (2014), Problem based learning and sustainable engineering education: Challenges for 21st century, $\mathrm{PhD}$ thesis, Aalborg University.

Hallstedt, S.I. (2017), "Sustainability criteria and sustainability compliance index for decision support in product development", Journal of Cleaner Production, Vol. 140, pp. 251-266. https://doi.org/10.1016/j.jclepro.2015.06.068

Kajikawa, Y. (2008), "Research core and framework of sustainability science”, Sustainability Science, Vol. 3 No. 2, pp. 215-239. https://doi.org/10.1007/s11625-008-0053-1

Leibrecht, S. (2005), "Fundamentals principles for CAD-based ecological assessment", The International Journal of Life Cycle Assessment, Vol. 10 No. 6, pp. 436-444. https://doi.org/10.1065/lca2005.08.217

Luglietti, R., Rosa, P., Terzi, S. and Taisch, M. (2016), "Life cycle assessment tool in product development: environmental requirements in decision making process", Procedia CIRP, Vol. 40, pp. 202-208. https://doi.org/10.1016/j.procir.2016.01.103

Mesquita, D., Alves, A.C., Goncalves Fernadez, S.R. and Lima, R.M. (2009), “A first year and first semester project-led engineering education approach", Proceedings First Ibero-American Symposium of Project Approaches in Engineering Education PAEE-2009, Guaimaraes, Portugal, July 21-22, 2009, pp. 181-189.

Murphy, C., Allen, D., Allenby, B., Davidson, C.I., Hendrickson, C. and Matthews, H.S. (2009), "Sustainability in engineering education and research at U.S. universities", Environmental Science \& Technology, Vol. 43 No. 15, pp. 5558-5564. https://doi.org/10.1021/es900170m

Nagel, R., Nagel, J., Esparragoza, I. and Schmidt, L. (2016), "Summit on global sustainability in engineering: rationale and planning phase", Proceeding of the 14th Multi-Conference for Engineering Education and Technology, San Jose, Costa Rica, July 20-22, 2016. https://doi.org/10.18687/laccei2016.1.1.200

OSHA (2017), Official page Occupational Safety and Health Administration. Recommended practices for safety and health programs. [online] OSHA. Available at: https:/www.osha.gov/shpguidelines/hazardidentification.html (accessed 03.04.2017).

Qian, Y., Huang, Z. and Yan, Z. (2007), "Integrated assessment of environmental and economic performance of chemical products using analytic hierarchy process approach", Chinese Journal of Chemical Engineering, Vol. 15 No. 1, pp. 81-87. https://doi.org/10.1016/s1004-9541(07)60037-8 
Rowe, D. (2007), "Education for a sustainable future", Science, Vol. 317 No. 5836, pp. 323-324. https://doi.org/10.1126/science.1143552

Sarkar, P., Joung, C.B., Carrell, J. and Feng, S.C. (2011), "Sustainable manufacturing indicator repository", 31st Computers and Information in Engineering Conference. https://doi.org/10.1115/detc2011-47491

Szendiuch, I.R. (2007), "Importance of Eco Design Implementation in Engineering Education", Proceedings of the 9th International Conference on Engineering Education, San Juan, PR, July 23-28, 2006.

UNESCO (2003), Engineering: issues, challenges and opportunities. [online] UNESCO Publishing. Available at: http://unesdoc.unesco.org/images/0018/001897/189753e.pdf (accessed 03.04.2017).

\section{Appendix: AID-DS forms}

Table 8. List of indicators associated to the impacts in the product

\begin{tabular}{|l|l|l|l|l|l|l|}
\hline \multirow{2}{*}{$\begin{array}{c}\text { Sustainability } \\
\text { Indicators }\end{array}$} & Definition & Units & \multicolumn{3}{|c|}{$\begin{array}{c}\text { Dimension } \\
\text { (Choose with ax }\end{array}$} & \multirow{2}{*}{ Code } \\
\cline { 4 - 6 } & & & Env & Eco & Soc & \\
\hline & & & & & & SI1 \\
\hline & & & & & & SI3 \\
\hline & & & & & & SI4 \\
\hline & & & & & & SI5 \\
\hline
\end{tabular}

Table 9. Values of sustainability indicators in the reference product

\begin{tabular}{|c|c|c|c|}
\hline $\begin{array}{c}\text { Indicators } \\
\text { (by Code) }\end{array}$ & Value & Units & Special Considerations /Assumptions \\
\hline S1 & & & \\
\hline S2 & & & \\
\hline S3 & & & \\
\hline S4 & & & \\
\hline
\end{tabular}

Table 10. Strategies description. Changes proposed to enhance the sustainability performance of the product

\begin{tabular}{|c|c|c|c|}
\hline No & Name & Description & Code \\
\hline Strategy 1 & & & $\mathbf{A 1}$ \\
\hline Strategy 2 & & & $\mathbf{A 2}$ \\
\hline Strategy 3 & & & $\mathbf{A 3}$ \\
\hline Strategy 4 & & & $\mathbf{A 4}$ \\
\hline
\end{tabular}

Table 11. Evaluation of alternatives

\begin{tabular}{|c|c|c|c|c|c|c|}
\hline \multirow{2}{*}{$\begin{array}{c}\text { Indicators } \\
\text { (by Code) }\end{array}$} & Reference & \multicolumn{4}{|c|}{$\begin{array}{c}\text { Strategies } \\
\text { (Values by Indicator) }\end{array}$} & Units \\
\cline { 2 - 7 } & RP & A1 & A2 & A3 & A4 & \\
\hline S1 & & & & & & \\
\hline S2 & & & & & & \\
\hline S3 & & & & & & \\
\hline S4 & & & & & & \\
\hline
\end{tabular}


Table 12. Comparison of alternatives. Normalized table

\begin{tabular}{|c|c|c|c|c|c|}
\hline \multirow{2}{*}{$\begin{array}{c}\text { Indicators } \\
\text { (by Code) }\end{array}$} & \multicolumn{5}{|c|}{$\begin{array}{c}\text { Strategies } \\
\text { (Values by Indicator - Normalized Values) }\end{array}$} \\
\cline { 2 - 6 } & $\mathrm{RP} / \mathrm{RP}$ & $\mathrm{A} 1 / \mathrm{RP}$ & $\mathrm{A} 2 / \mathrm{RP}$ & $\mathrm{A} 3 / \mathrm{RP}$ & $\mathrm{A} 4 / \mathrm{RP}$ \\
\hline S1 & 1.0 & & & \\
\hline S2 & 1.0 & & & & \\
\hline S3 & 1.0 & & & & \\
\hline S4 & 1.0 & & & & \\
\hline
\end{tabular}

Table 13. Synthesis of alternatives

\begin{tabular}{|c|l|l|l|}
\hline Strategies & Improved Indicators & Worsened Indicators & Overall discussion \\
\hline S1 & & & \\
\hline S2 & & & \\
\hline S3 & & & \\
\hline S4 & & & \\
\hline
\end{tabular}

Dr. Ivan Enrique Esparragoza, Professor of Engineering The Pennsylvania State University

25 Yearsley Mill Road, 19063 Media, United States

Email: iee1@psu.edu 